International Journal of Advancement in Life Sciences Research

Online ISSN: 2581-4877

journal homepage http://ijalsr.org

Original Article

\title{
Effect of Progressive Muscle Relaxation (PMR) on Blood Pressure among Patients with Hypertension
}

\author{
Ida Rosdiana*, Yanti Cahyati \\ Lecturer, Tasikmalaya Health Polytechnics Ministry of Health, Republic of Indonesia \\ *Correspondence E-mail : Idarosdiana_27@yahoo.co.id
}

\begin{abstract}
In the late 20th century, heart disease and blood vessels, including hypertension are expected to be the leading cause of death developed and developing countries, so that prevention and handling efforts need to be done through both pharmacological and non-pharmacological therapies. Nonpharmacological therapies including lifestyle modification, stress management, and anxiety are the first steps that must be taken. One of the efforts to manage stress and anxiety that can be done is by progressive muscle relaxation. The aim of this study was to obtain an overview of the effect of progressive muscle relaxation on blood pressure reduction in hypertensive patients. The research design used method quasi-experimental, with a pretest and posttest group design with a control group. The sampling technique was carried out by purposive sampling, totaling 52 people, namely 26 people in the intervention group and 26 people in the control group. Statistical analysis used was univariate, bivariate using dependent t-test (paired $t$-test) to test differences in blood pressure before and after exercise and independent t-test (unpaired $t$-test) to test differences in blood pressure after exercise in the control group and intervention group. The results showed that there were significant differences in the mean systolic and diastolic blood pressure between before and after PMR intervention ( $p$-value $=0,000)$, but there was no significant difference in the mean systolic and diastolic blood pressure after intervention in both groups of respondents. In the intervention group, there was a decrease in systolic BP of $24.54 \mathrm{mmHg}$ and a diastolic BP of $16.54 \mathrm{mmHg}$, whereas in the control group there was a decrease in systolic BP of $11.2 \mathrm{mmHg}$ and a diastolic TD of $5.5 \mathrm{mmHg}$. The study recommends the need for the use of therapeutic PMR as a complementary therapy in treating patients with hypertension and need further research on the effect of PMR modified with other nonpharmacologic therapies.
\end{abstract}

Keywords: Hypertension; Progressive Muscle Relaxation; Systolic BP, diastolic BP

\section{Introduction}

High blood pressure is prevalent all over the world. As per World Health Organization report, about $40 \%$ of people aged more than 25 years had hypertension in 2008 (WHO, 2013). Approximately 4 in 10 adults older than 25 years have hypertension, and in many countries another 1 in 5 has prehypertension. Increased BP was the cause of an estimated
9.4 million deaths and 162 million years of life lost in 2010 and the cause of $50 \%$ of heart disease, stroke, and heart failure (Campbell, et al., 2014).

In the algorithm for handling hypertension, non-pharmacological therapies including lifestyle modification, managing stress and anxiety are the first steps to be taken (Brunner 
\& Suddarth, 2000; Bhatt et al., 2007; Lewis et al., 2016). One of the efforts to manage stress and anxiety that can be done is progressive muscle relaxation, where the response from the relaxation technique is expected to inhibit the autonomic nervous system and the central nervous system, and will increase parasympathetic activity which will reduce the heart rate so cardiac output decreases and eventually blood pressure will also decrease (Brunner \& Suddarth, 2000; Hahn \& Kim, 2006; Sheu et al., 2003; Lewis et al., 2016).

Stress management through relaxation techniques can reduce blood pressure in the short and long term, but it is unfortunate that the use of progressive muscle relaxation as a therapy for hypertensive patients is still rare. Thus, researchers are interested in knowing how Progressive muscle relaxation affects blood pressure reduction in hypertensive patients in Tasikmalaya City?

\section{Methods}

\section{Study Design}

The research design used was quasiexperimental with pre and post-test and using a control group. The number of research samples was 52 people, namely 26 people in the intervention group and 26 people in the control group with a purposive sampling technique.

\section{Criteria Study}

The study inclusion criteria are based on patients hypertension with blood pressure $\geq$ $140 / 90 \mathrm{mmHg}$ in the age group minimal 35 years old with a written informed concern, have a mild level of activity, willing to do PMR exercise for 7 days and using the same antihypertensive drugs. The study exclusion criteria include patient who absent from programmed relaxation activities, intolerant of PMR activities, and patients experience health problems during intervention.

\section{Data Collection Procedure}

Assessment of patient demographic data, such as age, and sex was obtained from the patient's medical record. The patient's blood pressure was measured before intervention and after the intervention on the seventh day.

The data collection tool used was a digital sphygmomanometer to measure sample blood pressure and observation sheets to record patient's blood pressure before and after progressive muscle relaxation.

\section{The PMR Interventions}

Patients are recommended to do PMR exercises once a day for 7 days. The exercises involves tensing and relaxation cycles. The training starts with legs, proceeds to the muscles of the back, shoulders, neck, head, forehead, and end with concentrating on the whole body. At the same time encouraging a given individual to imagine himself/herself saying the word "relax" under his/her breath, each time he/she breathes out.

\section{Statistical Analysis}

Statistical analysis used was univariate, bivariate using dependent $t$-test (paired $t$-test) to test differences in blood pressure before and after PMR training and independent t-test (unpaired $t$-test) to test for blood pressure differences after PMR exercise in the control group and intervention group.

\section{Results}

\section{Univariate Analysis}

Table 1 Distribution of Age-Based Respondents

\begin{tabular}{|l|c|c|c|c|}
\hline \multicolumn{1}{|c|}{ Group } & Mean & SD & Min - Max & $95 \% \mathrm{Cl}$ \\
\hline Control & 57.96 & 11.501 & $40-80$ & $53.32-62.61$ \\
\hline Intervention & 54.85 & 7.933 & $40-75$ & $51.64-58.05$ \\
\hline
\end{tabular}


Table 2 Distribution of Respondents by Gender

\begin{tabular}{|l|c|c|c|c|}
\hline \multirow{2}{*}{ Variables } & \multicolumn{2}{|c|}{$\begin{array}{c}\text { Control Group } \\
(\mathrm{n}=26)\end{array}$} & \multicolumn{2}{c|}{$\begin{array}{c}\text { Intervention Group } \\
(\mathrm{n}=26)\end{array}$} \\
\cline { 2 - 5 } & $\mathrm{n}$ & $\%$ & $\mathrm{~N}$ & $\%$ \\
\hline Gender & & & & \\
\hline Male & 12 & 46.2 & 9 & 34.6 \\
\hline Women & 14 & 53.8 & 17 & 65.4 \\
\hline Total & 26 & 100 & 26 & 100 \\
\hline
\end{tabular}

Table 3 Distribution of Average Blood Pressure Before and After Intervention in the Control Group

\begin{tabular}{|l|c|c|c|c|c|}
\hline Variable & & Mean & SD & Min - Max & 95\% Cl \\
\hline Systolic Blood & Before & 157.35 & 13169 & $140-190$ & $152.03-162.67$ \\
\cline { 2 - 5 } Pressure & After & 146.15 & 14254 & $120-178$ & $140.40-151.91$ \\
\hline Diastolic Blood & Before & 95.77 & 9925 & $80-120$ & $91.76-99.78$ \\
\cline { 2 - 6 } Pressure & After & 90.27 & 7433 & $80-110$ & $87.27-93.27$ \\
\hline
\end{tabular}

Table 4 Distribution of Average Blood Pressure Before and After PMR in Intervention Group

\begin{tabular}{|l|c|c|c|c|c|}
\hline Variable & & Mean & SD & Min - Max & 95\% Cl \\
\hline Systolic Blood & Before & 163.85 & 17.798 & $140-197$ & $156.66-171.03$ \\
\cline { 2 - 5 } Pressure & After & 139.31 & 12.270 & $120-167$ & $134.35-144.26$ \\
\hline Diastolic Blood & Before & 105.69 & 10.661 & $85-128$ & $101.39-110.00$ \\
\cline { 2 - 5 } Pressure & After & 89.15 & 5.289 & $80-98$ & $87.02-91.29$ \\
\hline
\end{tabular}

2. Bivariate Analysis

Table 5 Distribution of Average Blood Pressure Before and After interventions in The Control Group and The Intervention

\begin{tabular}{|l|c|c|c|c|c|c|}
\hline Group & Blood Pressure & Mean & SD & SE & p-Value & n \\
\hline \multirow{3}{*}{ Control } & Systolic Before & 157.35 & 13.169 & 2.583 & 0.000 & 26 \\
& Systolic After & 146.15 & 14.254 & 2.795 & & \\
\cline { 2 - 7 } & Diastolic Before & 95.77 & 9.925 & 1.946 & 0.000 & 26 \\
& Diastolic After & 90.27 & 7.433 & 1.458 & & \\
\hline \multirow{3}{*}{ intervention } & Distolic Before & 163.85 & 17.798 & 3.491 & 0.000 & 26 \\
& Diastolic After & 139.31 & 12.270 & 2.406 & & \\
\cline { 2 - 7 } & Distolic Before & 105.69 & 10.661 & 2.091 & 0.000 & 26 \\
& Diastolic After & 89.15 & 5.289 & 1.037 & & \\
\hline
\end{tabular}

Table 6 Distribution of Differences in Mean Blood Pressure Before Intervention Between Control \& Intervention Groups

\begin{tabular}{|l|l|c|c|c|c|c|}
\hline Variables & Group & Mean & SD & SE & p-Value & $\mathbf{n}$ \\
\hline Before the intervention & & & & & & \\
\hline \multirow{2}{*}{ Systolic } & Control & 157.35 & 13.169 & 2.583 & \multirow{2}{*}{0.141} & 26 \\
\cline { 2 - 6 } & Intervention & 163.85 & 17.798 & 3.491 & & 26 \\
\hline Diastolic & Control & 95.77 & 9.925 & 2.583 & \multirow{2}{*}{0.001} & 26 \\
\cline { 1 - 6 } & Intervention & 105.69 & 10.661 & 2.091 & & 26 \\
\hline After Intervention & & & & & & \\
\hline Systolic & Control & 146.15 & 14.254 & 2.795 & 0.069 & 26 \\
\hline & Intervention & 139.31 & 12.270 & 2.406 & & 26 \\
\hline Diastolic & Control & 90.27 & 7.433 & 1.458 & 0.536 & 26 \\
\hline & Intervention & 89.15 & 5.289 & 1.037 & & 26 \\
\hline
\end{tabular}


Table 7 Comparison of Changes in Average Blood Pressure Before and After Intervention in The Control Group and Intervention

\begin{tabular}{|l|c|c|c|c|c|}
\hline Variable & Group & $\begin{array}{c}\text { Mean } \\
\text { Before }\end{array}$ & Mean After & Changes & Meaning \\
\hline $\begin{array}{l}\text { Systolic Blood } \\
\text { Pressure }\end{array}$ & Control & 157.35 & 146.15 & Down 11.2 & $\begin{array}{c}\text { Systolic blood } \\
\text { pressure decreases }\end{array}$ \\
\cline { 2 - 5 } & Intervention & 163.85 & 139.31 & Down 24.54 & $\begin{array}{c}\text { Systolic blood } \\
\text { pressure decreased }\end{array}$ \\
\hline $\begin{array}{l}\text { Diastolic Blood } \\
\text { Pressure }\end{array}$ & Control & 95.77 & 90.27 & Down 5.5 & $\begin{array}{c}\text { Diastolic blood } \\
\text { pressure decreased }\end{array}$ \\
\cline { 2 - 5 } & Intervention & 105.69 & 89.15 & Down 16.54 & $\begin{array}{c}\text { Diastolic blood } \\
\text { pressure decreased }\end{array}$ \\
\hline
\end{tabular}

\section{Discussion}

\section{Characteristics of Respondents}

\section{a. Age}

The results of the study found that the age of the respondents in the control group and the intervention group was quite varied. Out of the 26 respondents in the control group, the average age was 57.96 , while the intervention group had an average age of 54.85 . Based on the theory, one of the risk factors for hypertension is age. The incidence of hypertension increases with age (LeMone \& Burke, 2004; Martins et al., 2001).

Increased blood pressure with increasing age is often associated with changes in arterial and arteriolar stiffness, where large arterial stiffness is generally caused by arteriosclerotic structural changes and calcification. This increase is initially seen from the pressure waves from the arterioles to the heart during the spread of blood pressure waves and these waves arrive back during systolic causing an increase in systolic blood pressure and an increase in pulse (Pinto, 2007).

Increased vascular resistance in small blood vessels also causes diastolic blood pressure to increase at more than 50 years of age and although increased vascular resistance causes hypertension, increased stiffness of large arteries also causes an increase in systolic blood pressure after age 50 (Pinto, 2007). Other causes that influence the increase in blood pressure in the elderly includes decrease in baroreceptor sensitivity, increased response to sympathetic nerve stimulation, renal changes and sodium metabolism and changes in the relationship of rennin- aldosterone (Corwin, 2001; Lemone \& Burke, 2004; Pinto 2007).

\section{b. Gender}

The results of the univariate analysis showed that in the control group as many as 12 people (46.2\%) were male and 14 people (53.8\%) were female, while in the intervention group there were 17 (65.4\%) female and 9 ( 34.6\%) were male.

According to Yoon, et al. (2015) the prevalence of hypertension in men is similar to women. But women are protected from cardiovascular disease before menopause. Women who have not experienced menopause are protected by estrogen which plays a role in increasing levels of HighDensity Lipoprotein (HDL). High HDL cholesterol levels are a protective factor in preventing atherosclerosis. The effect of estrogen protection is considered as an explanation for the immunity of women in premenopausal age. In premenopause women begin to lose little by little the hormone estrogen which has been protecting blood vessels from damage. This process continues where the estrogen hormone changes its quantity according to the age of a woman naturally, which generally starts in women aged 45-55 years before age (Martins, et.al, 2001).

The high prevalence of hypertension occurs in postmenopausal women than in premenopausal women (Martins, et al. 2001; Reckelhoff, 2001; Pinto, 2007). Despite a decrease in estrogen production in the ovary, estrogen plays an important role in increasing blood pressure after menopause. Investigation of the biological effects of estrogen has been shown in the estrogen hormone derived from 
17-beta-estradiol, causing endothelial vasodilation. Furthermore, an endothelial function using acetylcholine stimulants in the arm veins is shown by reduced endothelial vasodilation associated with menopause, affecting endogenous estrogen in the regulation of blood pressure. Clinically shown that estrogen can regulate blood pressure response to stress stimulation.

\section{Differences in blood pressure in the intervention group and control group before intervention}

The results showed the average value of systolic blood pressure in the control group before the intervention was $157.35 \mathrm{mmHg}$ and diastolic blood pressure was $95.77 \mathrm{mmHg}$. The mean value of systolic and diastolic blood pressure in the intervention group before the intervention was $163.85 \mathrm{mmHg}$ and diastolic blood pressure was $105.69 \mathrm{mmHg}$.

The intervention group before PMR therapy showed an average systolic blood pressure that was $6.5 \mathrm{mmHg}$ higher than the control group and an average diastolic blood pressure was $9.92 \mathrm{mmHg}$ higher than the control group. The results of the further analysis showed that before the intervention there was no significant difference between the average systolic blood pressure of the respondents in the intervention group with a systolic blood pressure of the control group respondents ( $p$-value $=0.141$ ) The results of further analysis of diastolic blood pressure showed a significant difference between the average diastolic blood pressure of the respondents in the intervention group with a diastolic blood pressure of the control group respondents $(p$-value $=0.001)$.

Research respondents were hypertensive patients who sought treatment at the Health Center of Tasikmalaya which met the research inclusion criteria. Inclusion criteria included: hypertension patients with blood pressure $\geq$ $140 / 90 \mathrm{mmHg}$, patients aged at least 35 years, willing to carry out progressive muscle relaxation techniques once a day for 7 days, patients had mild activity levels, and used antihypertensive drugs according to health center medical service standards.

Respondents were selected into the intervention and control groups through simple random sampling method, by lottery using written papers of the intervention group or control group. All patients meeting the inclusion criteria have the same opportunity to be selected in the intervention or control group. All patients who became research respondents had undergone medical examinations by doctors who served in the Health Center. Antihypertensive pharmacological therapy is given when the patient first comes into a respondent including; furosemide tablet $40 \mathrm{mg}$ every 24 hours, Potassium Slow Release (KSR) tablet $600 \mathrm{mg}$ every 24 hours, Dexacap (Captopril) tablet $12.5 \mathrm{mg}$ every 8 hours. The therapy given is in accordance with medical service standards in the Health Center.

Diuretics are the first drug given to treat hypertension. Diuretics help the kidneys get rid of salt and water, which reduces the volume of fluid throughout the body, thereby reducing blood pressure. Diuretics also cause blood vessel dilation. Diuretics cause loss of potassium through the urine so that sometimes additional potassium or potassiumretaining drugs are given. Captopril is an Angiotensin Converting Enzyme inhibitor (ACE-inhibitor) which causes a decrease in blood pressure by dilating the arteries.

In the concept of theory and in the implementation of standard therapy for patients in the intervention and control groups before being done there is no difference. Researchers can conclude that all of the data can be collected for research purposes.

\section{Differences in blood pressure after PMR intervention in the intervention group and control group}

The results showed the average value of systolic blood pressure in the control group after intervention (consumption of hypertension drugs) was $146.15 \mathrm{mmHg}$ and diastolic blood pressure was $90.27 \mathrm{mmHg}$. The mean value of systolic blood pressure in the intervention group after intervention (consumption of hypertension drugs + PMR) was $139.31 \mathrm{mmHg}$ and diastolic blood pressure was $89.15 \mathrm{mmHg}$.

The intervention group after PMR therapy showed an average systolic blood pressure 
lower than $6.84 \mathrm{mmHg}$ compared to the control group and an average diastolic blood pressure lower by $1.12 \mathrm{mmHg}$ than the control group. The results of the further analysis showed that after the intervention there was no significant difference between the mean systolic blood pressure of the respondents in the intervention group with a systolic blood pressure of the control group respondents ( $p$ value $=0.069$ ). Likewise, with diastolic blood pressure after the intervention, there was no significant difference between the average diastolic blood pressure of the intervention group respondents with the diastolic blood pressure of the control group respondents $(p$ value $=0.536$ ) .

The results of this study are different from the results of Kumutha's research, (2014) which concluded that there were significant differences in the mean systolic and diastolic blood pressure in the intervention group when compared with the control group ( $p$-value $=$ $0.05)$. Likewise with the study of Patel, et al (2012) who found that there were significant differences between the mean systolic blood pressure between the intervention group and the control group $(p<0.005)$. However, Patel et al (2012) found no significant difference in the mean diastolic blood pressure between the intervention group and the control group ( $p>$ 0.005).

Although the results of the further analysis in this study showed no significant differences in the mean systolic and diastolic blood pressure between the intervention group and the control group ( $p>0.005$ ), it can be seen that there was a greater decrease in blood pressure in the intervention group respondents, who received standard therapy and performed PMR once a day for 7 days when compared to a decrease in blood pressure experienced by the control group who only received standard therapy from the Health Center.

The systolic blood pressure of the intervention group decreased by $24.54 \mathrm{mmHg}$, while the control group experienced a decrease in systolic blood pressure of $11.2 \mathrm{mmHg}$. The difference in the decrease in systolic pressure from the intervention group and the control group was $13.34 \mathrm{mmHg}$. As for diastolic blood pressure, there was a decrease of 16.54
$\mathrm{mmHg}$ in the intervention group and 5.5 $\mathrm{mmHg}$ in the control group. The difference in the decrease in diastolic blood pressure from the two groups is $11.04 \mathrm{mmHg}$.

\section{Differences in Blood Pressure Before and After PMR Intervention in the Intervention Group}

The results of the study in Table 4.7 showed the average systolic blood pressure before PMR in the intervention group was 163.85 $\mathrm{mmHg}$ while the average systolic blood pressure after PMR was $139.31 \mathrm{mmHg}$. Statistical test results obtained $p$-value 0.000 , it can be concluded that there is a significant difference in the average systolic blood pressure before and after PMR in the intervention group.

The average diastolic blood pressure before doing PMR in the intervention group is $\mathbf{1 0 5 . 6 9}$ $\mathrm{mmHg}$ while the average diastolic blood pressure after PMR is $89.15 \mathrm{mmHg}$. Statistical test results obtained $p$-value 0.000 , it can be concluded that there are significant differences in the average diastolic blood pressure before and after PMR in the intervention group.

PMR is a method to help reduce muscle tension so the body relaxes. It was first introduced by Edmund Jacobson in 1938. In his book, Jacobson explained that when muscle tension significantly decreases, the chance for disease emergence can be reduced. Jacobson also said that relaxation is the direct negative of nervous excitement. It is the absence of nerve-muscle impulse (Snyder \& Lindquist, 2010).

PMR was done by contracting and relaxing a group of muscles sequentially, namely the muscles of the hands, upper arms, forearms, forehead, face, jaw, neck, chest, shoulders, upper back, abdomen, thighs, and calves. Muscle contraction is done $5-10$ seconds and relaxation for about 10-20 seconds. The patient's attention is directed to being able to feel the difference between when the muscles are contracted and when they are relaxed. Exercise is done in a quiet room on a chair or comfortable bed that supports the body well. Patients are encouraged to wear comfortable, not tight clothing, and remove shoes, glasses and contact lenses. An important point of this 
exercise is to do it regularly every day for at least 15 minutes (Snyder \& Lindquist, 2010).

The purpose of relaxation exercises is to produce responses that can combat stress responses (Smeltzer \& Bare, 2008). Benefits of PMR are reducing anxiety, body oxygen consumption, the speed of metabolism, respiratory frequency, muscle tension, blood pressure systole, and diastole, premature ventricular contractions and increased brain alpha waves (Snyder \& Lindquist, 2010, Essa, et al., 2017).

Physiologically, stressful situations activate the hypothalamus which then controls two neuroendocrine systems, namely the sympathetic system and the adrenal cortex system. The sympathetic nervous system responds to nerve impulses from the hypothalamus by activating various organs and smooth muscles under its control, for example, it increases the speed of the heart rate, increases blood pressure, increases blood flow to the muscles and dilates the pupils (Smeltzer \& Bare, 2008).

The sympathetic nervous system also signals the adrenal medulla to release epinephrine and norepinephrine into the bloodstream. The adrenal cortex system is activated if the hypothalamus secretes $\mathrm{CRH}$, a chemical that acts on the pituitary gland located just below the hypothalamus. The pituitary gland then secretes the ACTH hormone, which is carried through the bloodstream to the adrenal cortex. This ACTH hormone will then stimulate the release of a group of hormones, including cortisol, which regulates blood sugar levels. ACTH also signals other endocrine glands to release about 30 hormones. The effects of the combination of various stress hormones carried through the bloodstream plus the sympathetic neural activity of the autonomic nervous system play a role in the fight or flight response (Mc Corry, 2007).

Smeltzer \& Bare (2002) said the purpose of relaxation training is to produce responses that can combat stress. Thus, when doing PMR calmly, relaxed and full of concentration (deep relaxation) against muscle tension and relaxation that is trained for 30 minutes then the secretion of $\mathrm{CRH}$ (corticotrophin releasing hormone) and ACTH (adrenocorticotropic hormone) in the hypothalamus decreases. The second decrease in hormone secretion causes the activity of the sympathetic nerve to decrease so that the release of adrenaline and noradrenaline decreases, resulting in a decrease in heart rate, dilated blood vessels, reduced vessel resistance and decreased heart pump so that the arterial blood pressure decreases (Sherwood, 2011).

PMR exercises have a significant impact on lowering blood pressure in patients with essential or primary hypertension. Impacts that occur include direct and long-term impacts. The direct impact of PMR therapy is a decrease in blood pressure, especially systolic in adults who take regular treatment. The results of this study also show that PMR training can have an impact on blood pressure reduction not only in patients with essential or primary hypertension but also in patients with secondary hypertension with other comorbidities.

Other results that are consistent with this study are research conducted by Hahn \& Kim (2014) which concluded that there were significant differences in the mean blood pressure between before and after doing PMR in the intervention group, where systolic blood pressure dropped by $20.6 \mathrm{mmHg}$ and diastolic blood pressure of $14.4 \mathrm{mmHg}$. The results of the study also concluded that PMR exercise has a beneficial effect in reducing blood pressure in the elderly.

The study of Patel et al. (2012) also showed a difference in systolic blood pressure meaningful pre and post PMR in the intervention group, but there were no significant differences in diastolic blood pressure. Although the mean systolic blood pressure of respondents who did PMR decreased when compared with the control group who had normal blood pressure there were still significant differences, meaning that PMR can reduce blood pressure but cannot return to normal blood pressure.

Hypertension is associated with an unhealthy lifestyle so the main recommendations that $\mathrm{WHO}$ recommends to manage and overcome it are by modifying lifestyles including controlling stress, anxiety or tension (Shinde, et al., 2013). Research also shows that 
progressive muscle relaxation therapy cannot be an alternative therapy (single therapy) but is a complementary therapy that helps antihypertension drug therapy in lowering blood pressure.

\section{Conclusion}

The intervention group that did PMR training and consumed anti-hypertensive drugs experienced a greater decrease in blood pressure compared to the control group who only received antihypertensive therapy. In the intervention group, there was a decrease in the average systolic blood pressure of 24.54 $\mathrm{mmHg}$ and a decrease in diastolic blood

\section{References}

Bhatt, S.P., Arafath, T.K. and Guleria, R., (2007). Nonpharmacological management of hypertension. Indian $\mathrm{J}$ Med Sci. 61(11), pp.616-24.

Campbell, N.R., Lackland, D.T., Niebylski, M.L. and World Hypertension League and International Society of Hypertension Executive Committees, (2014). High blood pressure: why prevention and control are urgent and important-a 2014 fact sheet from the World Hypertension League and the International Society of Hypertension. The Journal of Clinical Hypertension. 16(8), pp.551-553.

Cortas K, et al. (2016). Hypertension. Diakses pada tanggal 23 maret. http://emedicine.medscape.com/article/241381overview.

Corwin, E..J., (2000). Hand Book Pathophysiology edisi pertama. Alih bahasa: Brahm U. Jakarta: EGC.

Essa, R.M., Ismail, N.I.A.A., Hassan, N.I., (2017). Effect of progressive muscle relaxation technique on stress, anxiety, and depression after hysterectomy. Journal of Nursing Education and Practice. 7(7), pp. 77.

Hahn. K., \& Kim, S. (2006). Effect of progressive muscle relaxation technique on hypertension. American Journal of Hypertension. 6 (2), pp. 335-339

Kumutha, V., Aruna, S.\& Poongodi, R., (2014). Effectiveness of Progressive Muscle Relaxation Technique on Stress and Blood Pressure among Elderly with Hypertension. IOSR Journal of Nursing and Health Science. 3(4), pp.1-6.

LeMone, P. \& Burke, K., (2008). Medical surgical nursing critical thinking in client care. Canada: Pearson Education.

Lewis, S.L., Bucher, L., Heitkemper, M.M., Harding, M.M., Kwong, J., Roberts, D., (2016). Medical-Surgical Nursing-EBook: Assessment and Management of Clinical Problems, Single Volume. Elsevier Health Sciences.

Martins, D., Nelson, K., Pan, D., Tareen, N. \& Norris, K., (2001). The effect of gender on age-related blood pressure changes and the prevalence of isolated systolic hypertension among older adults: data from NHANES III. The Journal of Gender-Specific Medicine. 4(3), pp.10-3. pressure of $16.54 \mathrm{mmHg}$. As for the control group, there was an average decrease in systolic blood pressure of $11.2 \mathrm{mmHg}$ and a decrease in diastolic blood pressure of 5.5 $\mathrm{mmHg}$.

\section{Suggestions}

Suggestions from this study are the need to do more research on the effectiveness of progressive muscle relaxation combined with other therapies to reduce blood pressure in hypertensive patients, and progressive muscle relaxation therapy can be used as a complementary therapy in overcoming hypertension problems experienced by patients.

McCorry, L.K., (2007). Physiology of the autonomic nervous system. American Journal of Pharmaceutical Education, 71(4), 78.

Patel, H., Kathrotia, R., Pathak, N., Thakkar, H., (2012). Effect of relaxation technique on blood pressure in essential hypertension. Nat J Integr Res Med. 3, pp.10-4.

Pinto E. (2007). Blood pressure and ageing. Postgrad Med J. 83(976), pp.109-14.

Reckelhoff, J. F. (2001). Gender differences in the regulation of blood pressure. Hypertension. 37(5), pp.1199-208.

Sherwood, L., (2011). Fundamentals of human physiology. Cengage Learning. 4 edition, Cengage Learning.

Sheu, S., Irvin, B. L., Lin, H. S., Mar, C.L., (2003). Effects of progressive muscle relaxation on blood pressure and psychosocial status for clients with essential hypertension in Taiwan. Holistic Nursing Practice. 17(1), pp.41-47.

Shinde, N., Shinde, K.J., Khatri, S.M. and Hande, D., (2013). Immediate effect of Jacobson's progressive muscular relaxation in hypertension. Indian Journal of Physiotherapy and Occupational Therapy. 7(3), pp.234.

Smeltzer, S. C. \& Bare, B. G. (2008). Brunner\&Suddart: Textbook of medical-surgical nursing. Philadelphia: Lippincott.

Smeltzer, S. \& Brunner, B.B., Suddarth's. (2000). Textbook of Medical-Surgical Nursing. 9th ed.[e-book] Philadelphia: Lippincott, pp.241-242.

Snyder, M. \& Lindquist, R., (2002). An overview of complementary / alternative therapies. Complementary / Alternative Therapies in Nursing. 4th ed. New York, NY: Springer Publishing Co, pp.3-15.

World Health Organization, "Global brief on hypertension," 2013, http://apps.who.int/iris/bitstream/10665/79059/1/WHO_D CO_WHD_2013.2 eng.pdf?ua=1.

Yoon, S.S., Fryar, C.D. and Carroll, M.D., (2015). Hypertension prevalence and control among adults: United States, 20112014. US Department of Health and Human Services, Centers for Disease Control and Prevention, National Center for Health Statistics. 